Article

\title{
The Characteristics of the Exergy Reference Environment and Its Implications for Sustainability-Based Decision-Making
}

\author{
Kyrke Gaudreau $^{1{ }^{1} *}$, Roydon A. Fraser ${ }^{2}$ and Stephen Murphy ${ }^{1}$
}

1 Environment and Resource Studies, University of Waterloo, Waterloo, Ontario N2L 3G1, Canada; E-Mail: sd2murph@uwaterloo.ca

2 Mechanical and Mechatronics Engineering, University of Waterloo, Waterloo, Ontario N2L 3G1, Canada; E-Mail: rafraser@uwaterloo.ca

* Author to whom correspondence should be addressed; E-Mail: kgaudrea@uwaterloo.ca; Tel.: +1-519-781-7829.

Received: 4 May 2012; in revised form: 25 June 2012 / Accepted: 3 July 2012 /

Published: 5 July 2012

\begin{abstract}
In the energy realm there is a pressing need to make decisions in a complex world characterized by biophysical limits. Exergy has been promoted as a preferred means of characterizing the impacts of resource consumption and waste production for the purpose of improving decision-making. This paper provides a unique and critical analysis of universal and comprehensive formulations of the chemical exergy reference environment, for the purpose of better understanding how exergy can inform decision-making. Four related insights emerged from the analysis, notably: (1) standard and universal chemical exergy reference environments necessarily encounter internal inconsistencies and even contradictions in their very formulations; (2) these inconsistencies are a result of incompatibility between the exergy reference environment and natural environment, and the desire to model the exergy reference environment after the natural environment so as to maintain analytical relevance; (3) the topics for which exergy is most appropriate as an analytical tool are not well served by comprehensive reference environments, and (4) the inconsistencies point to a need for deeper reflection of whether it is appropriate to adopt a thermodynamic frame of analysis for situations whose relevant characteristics are non-thermodynamic (e.g., to characterize scarcity). The use of comprehensive reference environments may lead to incorrect recommendations and ultimately reduce its appeal for informing decision-making. Exergy may better inform decision-making by returning to process dependent reference states that model specific processes and situations for the purpose of engineering optimization.
\end{abstract}


Keywords: exergy; resource value; waste impact; sustainability assessment

\section{Introduction}

In the energy realm there is a need to make decisions about things that matter profoundly, in a world that is complex and characterized by uncertainty, disputed values and increasingly important biophysical limits [1-4]. Exergy analysis has been promoted as a thermodynamic tool for assessing energy and resource consumption and waste impact with the aim of providing more informed decision-making for progress towards sustainability [5-11]. For example, when discussing green energy technology, Rosen and Dincer [10] argue that exergy analysis provides information that is more useful and more meaningful than energy analysis. The notable benefits of the exergy concept has led to its application in several different disciplines, including: ecology and complex systems [5,12-16]; resource accounting and lifecycle assessments [7,9,11,17-21]; process optimization [10,22-25]; and even social theory [26].

Due to its increasing popularity, exergy is being improperly applied in certain situations, and the consequences of such applications are not fully appreciated. The concern is that improper application of exergy may lead to incorrect recommendations and ultimately reduce its appeal for informing decision-making. This paper reviews recent theory and practice of exergy analysis to highlight general challenges, and provide a unique and critical analysis of current major chemical reference environment formulations. The paper complements analyses of the temperature sensitivity of the exergy reference environment $[25,27]$. Three areas of focused that are explored in this thesis are: (1) inconsistent results due to applications of standard and universal exergy reference environments; (2) issues that arise in the attempt to formulate a chemical exergy reference environment similar to the natural environment; (3) the implications of adopting a thermodynamic (in this case exergy) frame of analysis for situations whose relevant characteristics (e.g., scarcity) are non-thermodynamic.

The outline of the paper is as follows: a brief description of inappropriate applications of exergy to characterize waste and resource value is presented to highlight some of the difficulties associated with comprehensive reference environments. Building from difficulties encountered characterizing wastes and resources, the authors provide an in-depth discussion of the predominant comprehensive exergy reference environment formulations to help explain the source of some of the limitations to using exergy. The authors conclude by arguing that exergy practitioners should apply exergy primarily for thermodynamic process optimization, whereby exergy is applied as a context- or environment-dependent decision-making tool and not as an intrinsic characteristic of matter. In this regard, the authors are proposing a return to the original purpose of exergy analysis: as a decision making tool for engineering systems analyses with the general goal of improving process efficiency as measured by work or work potential, or by identifying areas of inefficiency through exergy destruction or entropy production.

As a point of clarification, exergy refers to the total of thermal, mechanical, and chemical exergies as determined from temperature, pressure, and chemical potential gradients, respectively. When the exergy from only one or two of these three thermodynamic gradients is being considered appropriate adjectives will be used, for example, chemical exergy or thermal-mechanical exergy. 


\section{Rationale-The Limits of Chemical Exergy Analysis}

To better understand why a reassessment of chemical exergy analysis is needed, it is helpful to describe some limits to exergy analysis. To this end, this section provides a brief discussion of the challenges faced using exergy to characterize waste impact and resource consumption. A more in-depth discussion of this topic is provided in $[28,29]$.

\subsection{Exergy and Waste Impact}

The connection between the exergy content of waste and its environmental impact has been proposed by several authors [7,8,10,17,23,30-34]. For example, Ao et al. [22] argue that exergy can be viewed as "a measure of the departure of a substance from equilibrium with a specified reference environment, which is often modeled as the actual environment", and that "the exergy of an emission to the environment, therefore, is a measure of the potential of the emission to change or impact the environment". To this end, "the greater the exergy of an emission, the greater is its departure from equilibrium with the environment, and the greater may be its potential to change or impact the environment" [22]. Despite the simplicity of the argument linking exergy to waste impact, empirical evidence and more critical theoretical analysis have not confirmed the original premise: Rosen and Dincer [30,35] found little correlation between exergy and waste impact; others claim that exergy is not proportional to impact [36]; while others argue exergy cannot measure toxicity [33,37], which implies various forms of waste impact are incomparable with one another [38].

A second concern regarding exergy and waste impact is that beneath a seemingly simple argument is a fundamental confusion regarding what 'waste impact' entails. For some authors the exergy embodied in the waste is the minimum work required to bring the waste into equilibrium with the reference environment [30,32,34,35,39]. By contrast, others have claimed the exergy embodied in waste is a measure of work that may be produced by bringing the waste into equilibrium with the reference environment [17,40,41], and this interpretation is keeping within the logic of the exergy derivation. A third group [42] adopts both interpretations interchangeably. From a theoretical standpoint the interpretation that it may require work to bring a substance into equilibrium with the reference environment contradicts the very definition of exergy, and implies an improper interpretation of the fundamentals of exergy. The end result is there is no clear value to adopting an exergy perspective to characterize environmental impact of wastes, and if one does take this perspective they must address the somewhat arbitrary nature of the exercise.

\subsection{Exergy and Resource Value}

The connection between exergy and resource value relates to the observation that resource consumption is not well characterized using matter or energy (1st law of thermodynamics), primarily because both are conserved; instead, resource consumption is analogous to the degradation of the resource quality, which may be characterized using exergy [7,10,17,20,43-45]. In effect, the exergy content of a resource is a measure of the value of a resource [6,11,17,36,43,45-47], implying that the exergy content of the earth may even be a measure of the Earth's "natural capital" [43]. According to Valero et al. [19], "the thermodynamic value of a natural resource can be defined as the minimum 
work necessary to produce it with a specific structure and concentration from common materials in the environment". As will be shown later, this approach to thermodynamic value is rooted in chemical exergy.

The relationship between exergy and resource is a premise that guides analysis, but there has been seemingly little research, empirical or otherwise, to validate the original premise. To the best of our knowledge, the only empirical evidence comes from recent research by Valero [43], which was conceived for other purposes, but may inform this discussion regardless. Valero [43] compared the theoretical chemical exergy value of a mineral resource to the amount of actual work required to upgrade the resource from a mixture to the pure state, and to do so she produced two scaling factors, $k_{c h}$ and $k_{c}$ (the $k$-factors), that show the multiplicative difference between theoretical and experimental results. The equation for the $\mathrm{k}$-factors shown is shown in Equation (1):

$$
B_{c h}^{\exp }=k_{c h} * B_{c h}^{\text {theo }} \quad B_{c}^{\text {exp }}=k_{c} * B_{c}^{\text {theo }}
$$

where $B_{c h}{ }^{e x p}$ and $B_{c}{ }^{e x p}$ are the actual chemical and concentration work required to upgrade the mineral, respectively, while $B_{c h}{ }^{\text {theo }}$ and $B_{c}{ }^{\text {theo }}$ are the theoretical work requirements (i.e., the chemical and concentration exergies). The larger the $k$-factor the greater the disparity between actual (i.e., empirical) and theoretical work requirements to purify a mineral. It must be noted, however, that while Valero distinguishes between chemical and concentration exergy, they are interrelated (chemical exergy is based upon concentration exergy) and due to the derivation of exergy they cannot be separated [29] (an example of the chemical/concentration interrelationship is provided in Appendix B of [17]). For the purpose of this example, however, they will be treated as separate. Valero [43] compiled scaling factors for a variety of minerals, the first eighteen of which are listed in Table 1.

Table 1. Selected $k_{c h}$ and $k_{c}$ values — chemical and concentration exergy scaling factors.

\begin{tabular}{cccccc}
\hline Substance & $\boldsymbol{k}_{\boldsymbol{c}}$ & $\boldsymbol{k}_{\boldsymbol{c h}}$ & Substance & $\boldsymbol{k}_{\boldsymbol{c}}$ & $\boldsymbol{k}_{\boldsymbol{c h}}$ \\
\hline $\mathrm{Ag}$ & 7042 & 10 & $\mathrm{Cr}$ & 37 & 1 \\
$\mathrm{Al}$ & 2250 & 8 & $\mathrm{Cs}$ & $\mathrm{N} . \mathrm{A}$. & 1 \\
$\mathrm{As}$ & 80 & 10 & $\mathrm{Cu}$ & 343 & 80.2 \\
$\mathrm{Au}$ & 422,879 & 1 & $\mathrm{~F}$ & 2 & 1 \\
$\mathrm{Ba}$ & $\mathrm{N} . \mathrm{A}$ & 1 & $\mathrm{Fe}$ & 97 & 5.3 \\
$\mathrm{Be}$ & 112 & 1 & $\mathrm{Ga}$ & $\mathrm{N} . A$. & 1 \\
$\mathrm{Bi}$ & 90 & 10 & $\mathrm{Ge}$ & N.A. & 1 \\
$\mathrm{Cd}$ & 804 & 10 & $\mathrm{Hf}$ & N.A. & 1 \\
$\mathrm{Co}$ & 1261 & 10 & $\mathrm{Hg}$ & 1707 & 10 \\
\hline
\end{tabular}

Source: adapted from [43]; N.A. = value not provided by Valero.

While Table 1 is incomplete, it is generally representative of the k-values listed by Valero [43]. In general, $k_{c}$ fluctuates widely, from a low of unity to a high of over 400,000 , while $k_{c h}$ generally remains within one order of magnitude (from 1 to 10), with a high of 188 for uranium [43]. The fluctuations in $k_{c h}$ and $k_{c}$ shown in Table 1 imply there is little correlation between the theoretical exergy value and the empirical results, and indicate that it is difficult, if not impossible, to predict even approximate trends. While further validation is certainly necessary, preliminary interpretation of the data indicates that exergy may not exhibit the necessary properties to characterize resource value. 
Different possible interpretations for the wide divergence between theoretical exergy and its relationship to work production or resource value include [29]: (1) the incompatibility between the definition of exergy quality and resource quality; (2) the inability of exergy to characterize non work-producing resources via the concentration exergy; (3) the limitations of exergy due to constraints placed during its derivation; (4) inherent problems with the formulation of the exergy reference environment; and (5) the multiple perspectives applied to exergy analysis (as was previously noted with regards to the exergy content of wastes). This article contributes to the discussion by further exploring the chemical exergy reference environment, which is fundamental to the exergy concept, and for which a critical analysis of the standard reference environment formulations has not been provided to date (in the case of finite systems in contact with each other, the systems are each other's reference environments, and therefore the notion of a reference environment is still fundamental). After discussing the chemical exergy reference environment, we will return to the $k$-values once again, because they form an important part of the thermodynamics of scarcity, which appears to be what chemical exergy is in fact being used for in many cases.

\section{The Exergy Reference Environment}

One of the principal advantages of exergy as a thermodynamic concept is that it is fundamentally context sensitive in that the exergy of a substance must always be measured with respect to a reference environment [10,17,30,48] (we use the term "reference state" and "reference environment" interchangeably). A consequence of this context sensitivity is that exergy has no meaning without a reference environment [48], and has little comparative value without a universal and comprehensive reference environment. At issue then are whether or not a universal and comprehensive reference environment can and should be formulated, and what the implications are.

The following sections critically discuss the two principal universal comprehensive reference environment formulations: equilibrium reference environment and defined reference environment. Both formulations aim to provide a standard value for resources and wastes. Following the presentation of the two formulations, we discuss the implications of the exergy reference on the ability of exergy analysis to inform decision-making.

\subsection{Ahrendts' Equilibrium Reference Environment}

Ahrendts' [49] equilibrium reference environment was founded on three principles: (1) the reference environment should be in thermodynamic equilibrium; (2) the exergies of the substances should not be so high so as to mask irreversibilities and inflate process efficiencies; and (3) the reference environment should not reduce the appeal of exergy as a measure of worth, and should therefore assign value to scarce products from a thermodynamic and economic perspective. Ahrendts [49] postulated that with a fixed temperature and known original chemical components, equilibrium conditions for the Earth may be determined, and his model included the composition of the atmosphere and the ocean, and the 15 most abundant elements of the Earth's crust that accounted for 99 percent of the mass of the Earth's crust. The elements, in the correct concentrations, were allowed to react experimentally. To mimic the natural environment, Ahrendts [49] chose a model constrained to contain compounds in all three phases (solid, liquid and gas) so as to represent the land, the oceans and the air. 
The history of Ahrendts' [49] model development helps illustrate some of the difficulties of the exergy reference environment. Initially, Ahrendts [49] manipulated both the constraints on the equilibrium and the thickness of the Earth's crust. In a complete equilibrium there would be no atmospheric oxygen, which would of course not resemble our present atmosphere. To maintain atmospheric oxygen, the energy pathway that resulted in the formation of nitric acid was blocked. Using a constrained equilibrium, and a crustal thickness of 1 meter, Ahrendts [49] computed exergies similar to other authors (e.g., Gaggioli and Petit, Baehr and Schmidt, and Szargut). Despite the similarities, Ahrendts [49] discarded that possible reference state because it violated the principle of complete equilibrium, upon which his reference environment formulation was based.

Following the initial trial described above, Ahrendts [49] focused on equilibrium models by manipulating only the crustal thickness and removing the constraint on oxygen. Unfortunately, increasing the crustal thickness (and ostensibly making the exergy reference environment more similar to the natural environment) simply widened the discrepancy between the computed exergy values and accepted engineering practice. For example, at a 1000 meter crustal thickness, the model produced a context that Ahrendts [49] described as paradoxical because 'valuable oxygen' was burned in the presence of 'worthless' fossil fuels. Ahrendts [49] referred to his new models as being in complete equilibrium, although this is incorrect because he still constrained the model to remain in three phases, which only occurs at the triple point [50].

After discarding various alternatives, Ahrendts [49] settled on a model with a crustal thickness of one meter that produced exergy values that differed from what was empirically observed, but whose chemical exergy values were generally low, and where there was no issue of a high exergy for oxygen (and consequently a low exergy for fossil fuels). At this point, Ahrendts [49] claimed his three criteria were met.

Ahrendts' reference environment has been highly criticized for various reasons. Szargut et al. [18] note that the exergy values do not match empirical reality, which Ahrendts acknowledged. Valero et al. [19] argue Ahrendts' reference environment neglects many important metals not included in the 99 percent. Others note the Earth is not in thermodynamic equilibrium and therefore an equilibrium environment is irrelevant $[18,43]$.

A broader critique is that Ahrendts' approach was effectively a subjective exercise to provide objective and measurable value. Ahrendts was critiqued for his manipulation of crustal thickness and choice of initial chemical species of the model [19], and one might include temperature as another notable subjective parameter. Likewise, Ahrendts' second and third principles are entirely arbitrary, and yet have a great impact on the final choice for the reference environment (and consequently the exergy values). Ahrendts' principles were even in tension with one another, notably the conflict between having exergy values not be too high and yet not stray to far from empirical results. Finally, Ahrendts [49] even admits to choosing a final model based upon 'intuitive appeal'. The end result is that while Ahrendts [49] claimed his reference environment provides absolute and intrinsic exergies, this is simply not the case, and any application of Ahrendts' framework is subject to the same limitations. 


\subsection{Szargut's Defined Reference States}

The second standard reference state formulation discussed here is Szargut's [36] defined reference state, which appears to be popular within the engineering community [7,17,32,35,51]. Szargut's [36] defined reference states are predicated upon acknowledging that the world is an open system that will never achieve thermodynamic equilibrium due to the constant influx of solar energy, and therefore an equilibrium reference environment is inappropriate. To compensate for the non-equilibrium nature of the world, Szargut [36] proposed to define a "reference substance" for every element in the environment, to which the exergy of any other substance may be determined by a balanced chemical reaction between the specific substance, its reference substance, and other reference substances. Similar to Ahrendts' reference state, Szargut's [36] model contains compounds in the solid, liquid and gas phases. While a detailed description of Szargut's approach is beyond the scope of this paper, and is provided elsewhere $[28,36,43]$, we summarize the major points below.

The first step, and the key to Szargut's defined reference state is the choice of reference substances, which are chosen based on their natural abundance in the world and if they have a low Gibbs free energy of formation $\left(\Delta G_{f},\right)$; and this is illustrated by Szargut's two-step procedure: (1) among a group of potential reference substances for a given atom that are sufficiently abundant and have a sufficiently low Gibbs free energy of formation, choose the most abundant; (2) Among a group of potential reference substances that are sufficiently abundant, but none of which has a low enough $\Delta G_{f}$, choose the one with the lowest $\Delta G_{f}$ [36]. Once the reference substances have been chosen, their exergy values are determined based upon their molar concentrations (i.e., this is a concentration exergy) $[36,43]$.

The second step in Szargut's [36] is to use the exergy of reference substances to determine the exergy of pure elements using a reverse reaction of formation between the element of choice and its reference substance. This is perhaps best illustrated using an example. The reference reaction for the element calcium shown in Equation (2), where the reference substance for calcium is calcium carbonate, and oxygen and carbon dioxide are references substances necessary to balance the chemical equation [36]:

$$
\mathrm{Ca}+0.5 \mathrm{O}_{2}+\mathrm{CO}_{2} \Rightarrow \mathrm{CaCO}_{3}
$$

Given that the exergy values of oxygen, carbon dioxide and calcium carbonate are known (they are reference substances), the exergy of calcium can then be calculated using the reverse reaction of formation, as shown in Equation (3):

$$
b_{\text {ch,element }}^{o}=-\Delta_{r} G^{o}+\sum_{\text {products }} B_{c h}^{o}-\sum_{\text {reactants }} B_{c h}^{o}
$$

Once the exergy values of the elements are known, the exergies of all other compounds may be calculated using a reaction of formation, shown in Equation (4) [36]:

$$
b_{c h, \text { compound }}^{o}=\Delta_{f} G^{o}+\sum_{i} n_{i} b_{c h, i}^{o}
$$

where $b^{o}{ }_{c h, \text { compound }}$ is the standard chemical exergy of the compound; $\Delta_{f} G^{o}$ is the Gibbs free energy of formation of the compound; $n_{i}$ is the number of moles of element $I$; and $b_{c h, i}^{o}$ is the standard chemical 
exergy of element $i$. At this point, the exergy values of all compounds are essentially known. A graphical representation of Szargut's model is provided in Figure 1.

Figure 1. Graphical representation of Szargut's defined reference state.

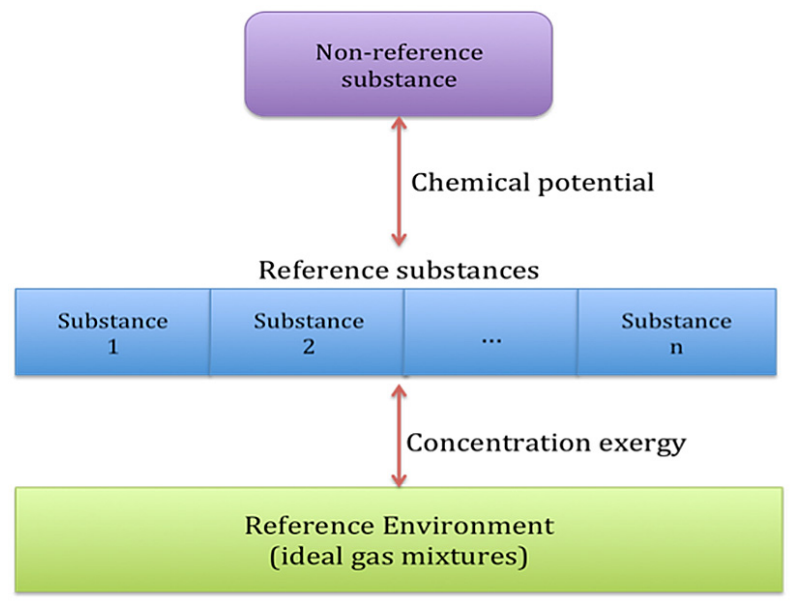

While Szargut's [36] model is conceptually simple, it contains a number of problems that have not be adequately addressed. First, Szargut is inconsistent in his use of chemical equilibrium. As noted above, Szargut et al. [18] critique Ahrendts' reference environment for being in thermodynamic equilibrium, when the world is obviously not in such a state, and yet Szargut's reference environment is described as being a "thermodynamically dead Earth", which is defined as [43] "a dead planet where all materials have reacted, dispersed and mixed and are in a hypothetical chemical equilibrium" (emphasis added). In other words, Szargut's reference environment is also developed as an equilibrium reference environment with simply different constraints than Ahrendts' equilibrium reference environment. At the same time, Valero [43] claims that a "thermodynamically dead" (i.e., equilibrium) reference environment would still have an atmosphere, hydrosphere, and continental crust, and yet provides no justification for why this is the case. More importantly, despite Szargut's reference environment being based on a "thermodynamically dead" planet, the exergies are still chosen to match empirical values in our far-from-equilibrium world.

A second problem with Szargut's formulation is that it is ambiguous in many regards. For example, several authors refer to Szargut's reference environment using four different terms: (1) a thermodynamically dead planet; (2) an entropic planet; (3) a crepuscular planet, and (4) a dissipated Earth $[18,19,43]$. While "thermodynamically dead" was defined above, "entropic planet", "dissipated Earth", and "crepuscular planet" appear to remain undefined, and therefore subject to loose interpretation. Likewise, Valero [43] notes that the stability and abundance thresholds are subjectively defined. To this end, Rosen and Dincer critique Szargut's formulation for being, among other things, "economic in nature", "vague and arbitrary with respect to the selection of reference substances", and "not similar to the natural environment" [30].

A third set of problems relates to the impossible exergy values generated by the model. When applying Szargut's approach, some substances end up with negative non-flow chemical exergies, and this is formally impossible based on the very definition of non-flow exergy [49,50]. Furthermore, even when the exergy values are positive, they often have no relation to the determination of useful work, 
because concentration exergy (as shown in the $k$-values) is neither a relevant nor even realistic means of calculating useful work production [29].

A final critique of Szargut's model is that it is inconsistently applied. In order to determine the exergy of liquid fuels, Szargut uses correlations based on the lower heating value of the fuel, and in doing so entirely bypasses his own reference environment $[36,43,52]$. This is notable because liquid fuels are potentially some of the few substances worth determining an exergy value for, since they are used to perform useful work. In other words, when measuring useful work production is actually a characteristic that matters, the defined reference state environment is considered inappropriate. We are ultimately forced to question what the point is of developing a comprehensive reference environment that is neither comprehensive nor relevant for important situations. To this end, Valero [43] acknowledges that "the reference environment based on Szargut's criterion should not be considered as a dead reference environment, but rather as a mathematical tool for obtaining standard chemical exergies of the elements". This admission effectively undermines the whole purpose of the exercise.

\section{Discussion: The Limitations of Standard Reference Environment Formulations}

While the reference environment formulations discussed above do not represent every possible universal and standardized reference environment, some key insights may still be elaborated. This section will elaborate upon four related issues pertaining to exergy and the reference environment; issues that develop a basic argument when taken as a package. The four issues are: (1) standard and universal chemical exergy reference environments necessarily encounter internal inconsistencies and even contradictions in their very formulations; (2) these inconsistencies are a result of incompatibility between the exergy reference environment and natural environment, and the desire to model the exergy reference environment after the natural environment so as to maintain relevance; (3) the topics for which exergy is most appropriate as an analytical tool are not well served by comprehensive reference environments; and (4) the inconsistencies point to a need for deeper reflection of whether it is appropriate to adopt a thermodynamic frame of analysis for situations whose relevant characteristics are non-thermodynamic.

First, the analysis of Szargut's and Ahrendts' reference environment formulations illustrated several inconsistencies and contradictions. For example, Szargut's formulation is simultaneously described as equilibrium and non-equilibrium, although it is clearly non-equilibrium. Furthermore, Szargut's model produces impossibly negative exergy values, which should be an early indicator that the underlying theory is not suitable. By contrast, Ahrendts faces his own set of challenges in that the more he tries to model his reference environment as being similar to the Earth in terms of mineral content (i.e., the thicker he makes the crust), the further his exergy values differ from empirically accepted reality: the very thing he is trying to model. Finally, both Ahrendts and Szargut attempt to reconcile their exergy values with empirical values despite acknowledging that the Earth is not in thermodynamic equilibrium, and therefore there is no reason to expect or desire similarities given that the implication of thermodynamic equilibrium for life on Earth is that there would be no life [53].

The second insight builds from the first and relates to how well the exergy reference environment formulations correspond to the natural world outside, and even whether they should. As previously noted, Ao et al. [22] claimed that the reference environment is often modeled as the actual 
environment, and this implies that the properties of exergy and natural environments may be reconciled. There is no a priori reason to assume that the exergy reference environment and the natural world are reconcilable, and in fact there are many reasons to argue just the opposite. To illustrate this, Table 2 provides a basic contrast between the characteristics of the exergy reference environment as defined by Rosen and Dincer [35] (and elaborated upon by us) compared to a restricted set of characteristics of the natural world [5,54-61].

Table 2. A basic contrast between the chemical exergy reference environment and the natural world.

\begin{tabular}{ll}
\hline The chemical exergy reference environment & The natural world \\
\hline $\begin{array}{l}\text { Infinite size: there are no discernable boundaries } \\
\text { although a boundary is posited between the }\end{array}$ & $\begin{array}{l}\text { Finite size: boundaries are very important } \\
\text { (eference environment and the system whose } \\
\text { exergy is being calculated }\end{array}$ \\
\hline $\begin{array}{l}\text { Infinite source and sink: nothing can harm the } \\
\text { reference environment }\end{array}$ & $\begin{array}{l}\text { Finite source and sink: displays catastrophic } \\
\text { behavior when it crosses a threshold }\end{array}$ \\
\hline In stable thermodynamic equilibrium & $\begin{array}{l}\text { Inherently non-equilibrium: one measure of } \\
\text { complexity is how far the environment is from } \\
\text { thermodynamic equilibrium }\end{array}$ \\
\hline Homogenous throughout & $\begin{array}{l}\text { Heterogeneous throughout: structures and scale are } \\
\text { important. Hierarchy results from self-organization }\end{array}$ \\
\hline Intensive state properties remain unaltered in time & $\begin{array}{l}\text { State properties change in time as a result of } \\
\text { evolution and development (among other things) }\end{array}$ \\
\hline
\end{tabular}

It should be immediately clear that the characteristics of the reference environment and the natural environment are diametrically opposed. For example, with regards to the use of exergy as a measure of waste impact, one must seriously question how anything can harm an environment that is infinite in size, is an infinite source and sink, and by its very definition never changes. This is not to say that waste items with higher exergy contents never have a higher capacity for impact. There are no doubts many instances in which the higher work producing potential of a waste increases its harm on the environment. However, to argue that exergy as defined through a universal reference environment is a valid measure of harm is simply erroneous [33,37].

The end result of mapping the exergy reference environment to the natural environment is the generation of a paradoxical situation: (1) exergy has little applicable value or meaning for waste impact and resource consumption if it is defined by a purely theoretical reference environment that has no similarity to the real world; and (2) the attempts to reconcile a standard or universal reference environment with the natural environment are bound to fail because the very characteristics of the natural environment are antithetical to those of the exergy reference environment.

The third argument is that the topics for which exergy is most appropriate as an analytical tool are not well served by comprehensive reference environments. For example, for energy systems not predicated upon chemical exergy (e.g., solar, wind, nuclear, tidal, geothermal, hydro), a standard chemical reference environment is irrelevant, and any addition of these energy types to the comprehensive reference environment will be ad hoc. Furthermore, for the case of chemical exergy, 
such as the combustion of fossil fuels or biomass, neither Ahrendts' nor Szargut's reference environments are applicable. In Ahrents' case, the situation was deemed a paradox, because the reference environment indicated a low value for fossil fuels and a high value for oxygen; the very opposite situation of what is generally considered to be the case. By contrast, Szargut does not use his reference environment to calculate the exergy of liquid fuels, but rather correlations based on the lower heating value of the fuel $[36,43,52]$. Effectively, neither reference environment is able to account for non-chemical work production, and nor are they internally able to account for essentially chemical combustion. Ultimately, we need to ask what useful work metrics do these reference environments actually account for within their own formulation.

To be clear, we are not implying that correlations to lower heating value are an inappropriate means of measuring how much useful work can be obtained from fossil fuels. What we are saying is that these correlations have nothing to do with comprehensive chemical exergy reference environments, nor with some idealized concentration exergy that is achieved through the movement of purely theoretical semi-permeable membranes. Ultimately we have a thermodynamic concept predicated on the determination of useful work production, but which is completely unable to provide sound framework to do so.

The inconsistencies noted above point to a need for deeper reflection about the exergy concept as it is being applied for resource accounting and waste impact. It is clear that chemical exergy, as determined by comprehensive reference environments, is not about useful work production; the items that may be characterized, however improperly, by a universal exergy reference environment (e.g., minerals) are not work producing, and therefore their chemical exergy content does not measure anything particularly useful nor relevant about them [29]. Instead, chemical exergy is really being applied as a means to quantify scarcity. Effectively, both Ahrendts' and Szargut's reference environments attempt to provide a thermodynamic (i.e., biophysical) value to scarce minerals and compounds, and this is even explicitly stated as the third principle of Ahrendts' approach [49]. Unfortunately, neither reference environment formulation is able to achieve this goal, as is illustrated by the $k$-values in Table 1 and Ahrendts" "paradox". But whether the goal is achieved or not, there is no good justification for developing a thermodynamics of scarcity in the manner that has been done. Things have value for many reasons, of which scarcity is only one measure [48]. Some very scarce products may still appear to have no value if they have no utility. Furthermore, to imply that scarcity is commensurable with work production is simply incorrect, but that is exactly what occurs when scarce substances are characterized in terms of their chemical exergy content.

While we recognize the desire to provide an alternative means of valuing natural resources than purely monetary value [62], the use of exergy as the common denominator is equally inappropriate. Both economic and exergy approaches to value are simply different forms of reductionism [38]. Furthermore, it is completely inappropriate to imply that an item has a higher work producing potential simply because it is scarcer in the environment, but that is exactly what is implied by quantifying scarce items through exergy.

An ecological example of thermodynamic reductionism is Jorgensen's [5] eco-exergy concept which converts DNA length into an organism's exergy by multiplying all organisms by the exergy content of detritus. However, if everything has the same base multiplier of the detritus exergy content, then organisms are not being compared on thermodynamic basis (at least not directly), but rather based 
on their DNA length [28]. In such situations, switching into a thermodynamic frame provides no obvious benefits, an opens up the analysis to further critique.

It is important to be clear that the discussion provided above does not critique all applications of exergy, but rather specifically to the use of exergy as an intrinsic and universal characteristic of all items, and as a means of valuing scarce items. In fact, despite the difficulties with standard reference environment formulations, exergy still has much value and insight to offer. The challenge is to work within the constraints of the exergy concept and its formulation [17].

\section{Exergy to Inform Decision-Making}

Building from the analysis in this paper, it appears necessary to move beyond attempts for a comprehensive standard reference environment that yields standard (universal) exergy values, as these produce exergy values with no obvious relevance or usefulness. Exergy is not an intrinsic characteristic of an item, and the exergy value of an item is a measure of thermodynamic distance between the item and a reference environment, and should not be attributed to the item, but rather it must be seen as being assigned to the combined 'system' of the item and its reference environment.

By stepping away from a universal reference environment, we may return to process dependent reference states - that is reference states developed to model specific processes and situations, and informed by the second law of thermodynamics [50,63]. Using process dependent reference environments allow exergy to be useful for many applications, including: (a) efficiency comparisons between disparate systems [e.g., comparing an internal combustion engine (Carnot limited heat engine) to a fuel cell (non-heat engine) via a second law efficiency]; (b) inefficiency magnitude identification within a given system (e.g., quantifying the work potential lost during heat transfer in a furnace); (c) inefficiency location identification within a given system (e.g., identifying the heat transfer to the boiler of a Rankine cycle system as a major location for work potential loss); and (d) enabling optimization of a given system (e.g., determining an optimum radiator temperature by minimizing exergy destruction).

In many situations the useful work that may be obtained from an item (e.g., coal) will be more or less identical simply because the process (combustion) and the relevant chemical species of the atmospheric are the same, and the temperature is within an acceptable range. While for the sake of simplicity and ease of communication, there is merit in attributing this useful work potential to the coal itself, this useful work is in fact equally dependent upon the process (combustion) and the reference environment. Furthermore, it is important to be clear that in process dependent models, exergy is seen as measuring the thermodynamic efficiency of a process (e.g., a conversion process) as opposed to characterizing a specific object (e.g., the exergy content of tin). While this difference appears subtle at times, these two perspectives of exergy represent fundamentally different conceptions of the exergy concept.

As a final point of note, we return to the issue of when there is merit in framing the analysis in terms of exergy. It is worth noting that exergy destruction minimization is effectively the same as entropy generation minimization through the Guoy-Stodola theorem. However, exergy is useful because it is based in units of work (e.g., kJ), which in general is easier for decision makers to comprehend than entropy units (e.g., kJ/K). In other instances, the benefit of an exergy framing is less certain. For 
example, while exergy is promoted as a means of improving lifecycle assessments [7,17,45,51] (and some exergy-based LCAs even predate generalized approaches to LCA), many lifecycle assessments already contain quality factors that relate to the question of useful work. Since the quality factors are already present, it is debatable whether significant further insight may be gained by explicitly adopting exergy. Ultimately, it is up to the analyst to adopt the most appropriate method of analysis for the case at hand, as opposed to pre-analytically framing the analysis through a particular lens [64], such as the exergy lens.

\section{Conclusions}

This paper provides a critical analysis of universal and comprehensive formulations of the chemical exergy reference environment, for the purpose of better understand how exergy can inform decision-making. By analyzing the theory and practice of Ahrendts' [49] and Szargut's [36] reference environment formulations, three related insights emerged, notably: (1) standard and universal chemical exergy reference environments necessarily encounter internal inconsistencies and even contradictions in their very formulations; (2) these inconsistencies are a result of incompatibility between the exergy reference environment and natural environment, and the desire to model the exergy reference environment after the natural environment so as to maintain relevance; (3) the topics for which exergy is most appropriate as an analytical tool are not well served by comprehensive reference environments, and (4) the inconsistencies point to a need for deeper reflection of whether it is appropriate to adopt a thermodynamic frame of analysis for situations whose relevant characteristics (e.g., scarcity) are non-thermodynamic.

Building from the analysis in this paper, we argue it is necessary to move beyond attempts for a comprehensive standard reference environment that yields standard (universal) exergy values and instead return to process dependent reference states; that is reference states developed to model specific processes and situations. Using process dependent reference environments allow exergy to be useful for many applications, including: (a) efficiency comparisons between disparate systems; (b) inefficiency magnitude identification within a given system; (c) inefficiency location identification within a given system; and (d) enabling optimization of a given system.

The analysis of Szargut's and Ahrendts' reference environment formulations reveal an underlying attempt to provide a biophysical means of value all objects, in this case based on their scarcity. While a thermodynamics of scarcity may be intuitively pleasing, and may provide a common metric by which all things (both work producing and not) can be characterized, we are concerned that such an interpretation of exergy ignores the intent of exergy analysis, which is to characterize and optimize work producing systems. On a more philosophical level, this attempt to reduce all means of value to exergy is no different than when economists attempt to value everything in monetary terms. If it is clearly wrong to value everything in terms of money, the same can be said of exergy. Many things that matter have no value with regards to their exergy content, and attempting to characterize them in terms of exergy does an injustice to all concerned.

The initial exploration of comprehensive and universal exergy reference environments was beneficial because it provides an opportunity for deeper critical analysis of the opportunities and limitations of the exergy concept. At this point, however, the continued application of comprehensive 
reference environments for the purpose of characterizing resources and wastes, and even process optimization, risks reducing both the usefulness and credibility of exergy for informing decision-making. Now is the time to close the door on such applications, unless a complete reformulation of the concept is undertaken so as to avoid the limitations discussed above, while recognizing that such a reformulation may not even be possible. While many of the insights developed above are probably inherently recognized by many exergy practitioners (e.g., [65]), these problems have not been sufficiently nor formally recognized in the exergy literature.

By recognizing and working within the constraints of exergy, the authors believe that exergy may still inform decision-making for progress towards sustainability. To do so, however, requires a deeper discussion of what insights can be obtained from thermodynamic analyses and what tradeoffs occur when the frame of reference becomes thermodynamic.

\section{Acknowledgments}

The authors would like to acknowledge the National Science and Engineering Research Council, whose support made this research possible. We also acknowledge the helpful comments from the reviewers.

\section{References}

1. Giampietro, M.; Allen, T.F.H.; Mayumi, K. The epistemological predicament associated with purposive quantitative analysis. Ecol. Complex. 2006, 3, 307-327.

2. Funtowicz, S.O.; Ravetz, J.R. Science for the post-normal age. Futures 1993, 25, 739-755.

3. Murray, J.; King, D. Climate policy: Oil's tipping point has passed. Nature 2012, 481, 433-435.

4. Giampietro, M.; Mayumi, K. The Biofuel Delusion: The Fallacy of Large-Scale Agro-Biofuel Production; Earthscan: London, UK, 2009.

5. Jorgensen, S.E. Eco-Exergy as Sustainability; WIT Press: Boston, MA, USA, 2006; Volume 16.

6. Rosen, M.A. Can exergy help us understand and address environmental concerns? Exergy 2002, 2, 214-217.

7. Cornelissen, R.L. Thermodynamics and Sustainable Development-The Use of Exergy Analysis and the Reduction of Irreversibility; University of Groningen: Groningen, The Netherlands, 1997.

8. Dincer, I.; Rosen, M.A. Exergy-Energy, Environment and Sustainable Development, 1st ed.; Elsevier: Oxford, UK, 2007.

9. Hepbasli, A. A key review on exergetic analysis and assessment of renewable energy resources for a sustainable future. Renew. Sustain. Energy Rev. 2008, 12, 593-661.

10. Rosen, M.A.; Dincer, I.; Kanoglu, M. Role of exergy in increasing efficiency and sustainability and reducing environmental impact. Energy Policy 2008, 36, 128-137.

11. Wall, G.; Gong, M. On exergy and sustainable development-Part 1: Conditions and concepts. Exergy 2000, 1, 128-145.

12. Kay, J.J.; Boyle, M. Self-organizing, holarchic open systems (SOHO). In The Ecosystem Approach: Complexity, Uncertainty, and Managing for Sustainability; Waltner-Toews, D., Kay, J.J., Lister, N.-M., Eds.; Columbia University Press: New York, NY, USA, 2008.

13. Bastianoni, S.; Marchettini, N. Emergy/exergy ratio as a measure of the level of organization of systems. Ecol. Model. 1997, 99, 33-40. 
14. Kay, J.J.; Allen, T.; Fraser, R.; Luvall, J.; Ulanowicz, R. Can we use energy based indicators to characterize and measure the status of ecosystems, human, disturbed and natural. In Proceedings of the International Workshop-Advances in Energy Studies: Exploring Supplies, Constraints and Strategies, Porto Venere, Italy, 23-27 May 2001.

15. Ulgiati, S. Emergy and exergy analyses: Complementary methods or irreducible ideological options. Energy 2005, 30, 1953-1988.

16. Ulanowicz, R.E.; Jorgensen, S.E.; Fath, B.D. Exergy, information and aggradation: An ecosystems reconciliation. Ecol. Model. 2006, 198, 520-524.

17. Wall, G. Exergy - A Useful Concept Within Resource Accounting; Institute of Theoretical Physics: Goteborg, Sweden, 1977.

18. Szargut, J.; Valero, A.; Stanek, D.; Alicia, V. Towards and international legal reference environment. In Proceedings of 18th International Conference on Efficiency, Cost, Optimization, Simulation and Environmental Impact of Energy Systems (ECOS 2005), Trondheim, Norway, 20-22 June 2005; pp. 409-420.

19. Valero, A.; Ranz, L.; Botero, E. Exergetic evaluation of natural mineral capital (1) Reference environment methodology. In Proceedings of 15th International Conference on Efficiency, Costs, Optimization, Simulation and Environmental Impact of Energy Systems (ECOS 2002), Berlin, Germany, 3-5 July 2002; pp. 56-61.

20. Gong, M.; Wall, G. On exergy and sustainable development-Part 2: Indicators and methods. Exergy 2000, 1, 17.

21. Hermann, W.A. Quantifying global exergy resources. Energy 2006, 31, 1685-1702.

22. Ao, Y.; Gunnewiek, L.; Rosen, M.A. Critical review of exergy-based indicators for the environmental impact of emissions. Int. J. Green Energy 2008, 5, 87-104.

23. Crane, P.; Scott, D.S.; Rosen, M.A. Comparison of exergy of emissions from two energy conversion technologies, considering the potential for environmental impact. Int. J. Hydrog. Energy 1992, 17, 345-350.

24. Dincer, I.; Rosen, M.A. The intimate connection between exergy and the environment. In Thermodynamic Optimization of Complex Energy Systems; Bejan, A., Mamut, E., Eds.; Kluwer Academic Publishers: Dordrecht, The Netherlands, 1999; Volume 1, pp. 221-230.

25. Utlu, Z.; Hepbasli, A. Energetic and exergetic assessment of the industrial sector at varying dead (reference) state temperatures: A review with an illustrative example. Renew. Sustain. Energy Rev. 2008, 12, 1277-1301.

26. Spiegelman, E; Spiegelman, G.; Spiegelman, J. Money as social exergy. J. Bioecon. 2007, 9, 265-277.

27. Al-Muslim, H.; Dincer, I.; Zubair, S.M. Effect of reference state on exergy efficiencies of oneand two-stage crude oil distillation plants. Int. J. Therm. Sc. 2005, 44, 65-73.

28. Gaudreau, K. Exergy Analysis and Resource Accounting. Master's Thesis, University of Waterloo, Waterloo, Canada, 2009.

29. Gaudreau, K.; Fraser, R.; Murphy, S. The tenuous use of exergy as a measure of resource value or waste impact. Sustainability 2009, 1, 1444-1463.

30. Rosen, M.A.; Dincer, I. On exergy and environmental impact. Int. J. Energy Res. 1997, 21, 643-654. 
31. Huang, L.Q.; Chen, G.Q.; Zhang, Y.; Chen, B.; Luan, S.J. Exergy as a unified measure of water quality. Commun. Nonlinear Sci. Numer. Simul. 2007, 12, 663-672.

32. Chen, G.Q.; Ji, X. Chemical exergy based evaluation of water quality. Ecol. Model. 2007, 200, 259-268.

33. Ayres, R.U.; Ayres, L.W.; Martinas, K. Exergy, waste accounting, and life-cycle analysis. Energy 1998, 23, 355-363.

34. Sciubba, E. Exergy as a direct measure of environmental impact. ASME Adv. Energy Syst. Div. 1999, 39, 571-581.

35. Rosen, M.A.; Dincer, I. Exergy analysis of waste emissions. Int. J. Energy Res. 1999, 23, 1153-1163.

36. Szargut, J. Exergy Method-Technical and Ecological Applications; WIT Press: Boston, MA, USA, 2005.

37. Favrat, D.; Marechal, F.; Epelly, O. The challenge of introducing an exergy indicator in a local law on energy. Energy 2008, 33, 130-136.

38. Martinez-Alier, J.; Munda, G.; O’Neill, J. Weak comparability of values as a foundation for ecological economics. Ecol. Econ. 1998, 26, 277-286.

39. Creyts, J.C.; Carey, V.P. Use of extended exergy analysis as a tool for assessment of the environmental impact of industrial processes. Presented at the ASME Advanced Energy Systems Division, Dallas, TX, USA, 16-21 November 1997.

40. Hellstrom, D. An exergy analysis for a wastewater treatment plant: An estimation of the consumption of physical resources. Water Environ. Res. 1997, 69, 44-51.

41. Hellstrom, D. Exergy analysis of nutrient recovery processes. Water Sci. Technol. 2003, 48, $27-36$.

42. Zaleta-Aguilar, A.; Ranz, L.; Valero, A. Towards a unified measure of renewable resources availability: The exergy method applied to the water of a river. Energy Convers. Manag. 1998, 39 , 1911-1917.

43. Valero, A. Exergy Evolution of the Mineral Capital on Earth. Ph.D. Dissertation, University of Zaragoza, Zarazoga, Spain, 2008.

44. Connelly, L.; Koshland, C.P. Exergy and industrial ecology_Part 1: An exergy-based definition of consumption and a thermodynamic interpretation of ecosystem evolution. Exergy 2001, 1, 146-165.

45. Cornelissen, R.L.; Hirs, G.G. The value of the exergetic life cycle assessment besides the LCA. Energy Convers. Manag. 2002, 43, 1417-1424.

46. Sciubba, E. Cost analysis of energy conversion systems via a novel resource-based quantifier. Energy 2003, 28, 457-477.

47. Brodianski, V.M. Earth's available energy and the sustainable development of life support systems. In Encyclopedia of Life Support Systems; Unesco: Oxford, UK, 2011.

48. Valero, A. Exergy accounting: Capabilities and drawbacks. Energy 2006, 31, 164-180.

49. Ahrendts, J. Reference states. Energy 1980, 5,666-677.

50. Bejan, A. Advanced Engineering Thermodynamics, 2nd ed.; Wiley-Interscience: New York, NY, USA, 1998; p. 850.

51. Wall, G. Molndal, Sweden. Exergetics. Unpublished work, 1998.

52. Morris, D.R.; Szargut, J. Standard chemical exergy of some elements and compounds on the planet earth. Energy 1986, 11, 733-755. 
53. Schneider, E.D.; Kay, J.J. Life as a manifestation of the second law of thermodynamics. Math. Comput. Model. 1994, 19, 25-48.

54. Gattie, D.K.; Kellam, N.N.; Turk, H.J. Informing ecological engineering through ecological network analysis, ecological modelling, and concepts of systems and engineering ecology. Ecol. Model. 2007, 208, 25-40.

55. Kay, J.J.; Schneider, E.D. Thermodynamics and measures of ecological integrity. In Proceedings of International Symposium on Ecological Indicators, Fort Lauderdale, FL, USA, 16-19 October 1992.

56. Lovelock, J. Gaia: A New Look at Life on Earth; Oxford University Press: New York, NY, USA, 1989.

57. Kay, J.J.; Boyle, M.; Regier, H.A.; Francis, G. An ecosystem approach for sustainability: Addressing the challenge of complexity. Futures 1999, 31, 721-742.

58. Ulanowicz, R.E. An hypothesis on the development of natural communities. J. Theor. Biol. 1980, $85,223-245$.

59. Odum, H.T. Environmental Accounting: Emergy and Environmental Decision Making; John Wiley: New York, NY, USA, 1996.

60. Ulgiati, S.; Bargigli, S.; Raugei, M. An emergy evaluation of complexity, information and technology, towards maximum power and zero emissions. J. Clean. Product. 2007, 15, 1359-1372.

61. Schneider, E.D.; Sagan, D. Into the Cool, 1st ed.; University of Chicago Press: Chicago, MI, USA, 2005.

62. Hall, C.S.; Klitgaard, K.A. The need for a new, biophysical-based paradigm in economics for the second half of the age of oil. Int. J. Transdiscipl. Res. 2006, 1, 4-22.

63. Gaggioli, R.A.; Petit, P.J. Use the second law, first. Chemtechs 1977, 7, 496-506.

64. Giampietro, M. Multi-Scale Integrated Analysis of Agroecosystems; CRC Press: Boca Raton, FL, USA, 2004.

65. Giampietro, M.; Mayumi, K. Complex systems thinking and renewable energy systems. In Biofuels, Solar and Wind as Renewable Energy Systems; Pimentel, D., Ed.; Springer Netherlands: Dordrecht, The Netherlands, 2008; pp. 173-213.

(C) 2012 by the authors; licensee MDPI, Basel, Switzerland. This article is an open access article distributed under the terms and conditions of the Creative Commons Attribution license (http://creativecommons.org/licenses/by/3.0/). 